\title{
Impact of surgeon learning curve in minimally invasive radical hysterectomy on early stage cervical cancer patient survival
}

\author{
L. Pedone Anchora ${ }^{1}$, N. Bizzarri ${ }^{1}$, V. Gallotta ${ }^{1}$, V. Chinntera ${ }^{2}$, F. Fanfani $^{1,3}$, A. Fogotti $^{3}$, \\ F. Cosentino ${ }^{4}$, G. Vizziellit ${ }^{1}$, V. Carbone ${ }^{1}$, G. Ferrandina ${ }^{1,3}$, G. Scambia ${ }^{1,3}$
}

${ }^{\prime}$ Fondazione Policlinico Universitario A. Gemelli, IRCCS, UOC Ginecologia Oncologica, Dipartimento per la salute della Donna e del Bambino e della Salute Pubblica, Roma, Italy; ${ }^{2}$ Department of Gynecologic Oncology, University of Palermo, Palermo, Italy; ${ }^{3}$ Università Cattolica del Sacro Cuore, Istituto di Ginecologia e Ostetricia, Roma, Italy; ${ }^{4}$ Gemelli Molise, Dipartimento di Oncologia, UOC Ginecologia Oncologica, Campobasso, Italy.

Correspondence at: Luigi Pedone Anchora, Fondazione Policlinico Universitario A. Gemelli, IRCCS, UOC Ginecologia Oncologica, Dipartimento per la salute della Donna e del Bambino e della Salute Pubblica, Roma, Italy. E-mail: luigi.us@hotmail.it. Phone number 00393497237807.

\section{Abstract}

Background: Recently, it has been sustained that only surgeons skilled in minimally invasive radical hysterectomy (MI-RH) could provide valuable oncological outcomes in early-stage cervical cancer. Still, literature lacks data correlating surgeon experience with patient survival rate. We aimed to investigate the impact of surgeon training on this rate.

Methods: This is a retrospective study of 243 early-stage cervical cancer treated with MI-RH. Multiple regression analyses were undertaken to investigate the impact of the surgeons learning curve, according to the number of MI-RH, on patients prognosis.

Results: A steady trend of reduction in disease recurrence risk is associated with increased surgeon experience. The peak of the learning curve was shown at the 19th MI-RH (hazard ratio of disease-free survival: 0.321 ; 95\% CI: $0.140-0.737 ; p=0.007)$. The 3 years disease-free survival that a surgeon could provide to patients is significantly lower at the beginning of his/her learning path comparing to what he/she could guarantee once adequate experience had been achieved $(75.4 \%$ and $91.6 \%$ respectively, $p=0.005)$. Surgeon experience appears to be an independent prognostic factor.

Conclusion: The experience that a surgeon can achieve practicing in MI-RH significantly influences oncological outcomes of early-stage cervical cancer patients. Future studies comparing minimally invasive and open surgery should take this into account. It would be advisable that the scientific community precisely establishes the minimum training required in the field of MI-RH for early-stage cervical cancer.

Key words: cervical cancer, minimally invasive, radical hysterectomy, experience, learning curve, laparoscopy.

\section{Background}

Radical hysterectomy with pelvic lymphadenectomy is the main treatment for women suffering from early-stage cervical cancer (Bansal et al., 2009; NCCN Cervical Cancer Guidelines, 2019) and has been traditionally carried out by open radical surgery through a laparotomy incision.

During the last decades, minimally invasive radical hysterectomy (MI-RH) for early-stage cervical cancer patients became increasingly popular on the basis of several retrospective studies (Diver et al., 2017; Nam et al., 2012; Corrado et al., 2018; Laterza et al., 2016; Gallotta et al., 2018; Barletta et al., 2015) and two meta-analyses reporting equivalent oncological outcomes between MI-RH and open radical hysterectomy $(\mathrm{O}-\mathrm{RH})$, in the face of reduced intra- and post-operative complications, estimated blood loss, and hospitalisation time (Diver et al., 2017; Nam et al., 2012; Corrado et al., 2018; Park et al., 2017; Lee et al., 2011; Wang et al., 2015; Cao et al., 2015). 
Recently, a multicenter phase III prospective, randomised study comparing MI-RH vs O-RH failed to achieve the primary end-point (i.e. noninferiority of MI-RH in terms of 5-yr disease free survival), due to the documentation of a fourfold increase of hazard ratio for recurrence of disease, leading to the premature closure of the study for safety issues (Ramirez et al., 2018).

These unexpected results rapidly led to contrasting reactions within the scientific community, modifying current ideas regarding the best surgical approach in early-stage cervical cancer and, at the same time, causing still ongoing controversial opinions, including the potential role of Gynaecologic Oncology Surgeon (GOS) learning of the minimally invasive approach, which must require specific skills (Kimmig and Ind, 2018; Nezhat et al., 2019; Leitao, 2018; Vergote et al., 2019).

It has been argued that minimally invasive procedures performed by surgeons who are not adequately skilled could have affected survival results of MI-RH (Leitao, 2018). It is surprising that, despite the great interest about the potential impact of the surgeon experience in MI-RH on the oncological outcomes in early-stage cervical cancer, the majority of previous studies evaluated the surgeon learning curve on the basis of the short-term outcomes only (i.e. operative time, complications, conversion rate etc.), or the comparison of survival measures according to time intervals (Yim et al., 2013; Madhuri et al., 2021; Hwang et al., 2012; Oyama et al., 2019; Chong et al., 2009; Cusimano et al., 2019; Liu et al., 2019).

The aim of this study is to investigate whether the surgeon learning curve for MI-RH, evaluated in terms of number of performed procedures, might have an impact on early-stage cervical cancer patient survival.

\section{Materials and methods}

This is a single centre, retrospective study including patients affected by histologically confirmed cervical cancer from Gynaecologic Oncology Units of Fondazione Policlinico-Universitario A. Gemelli-IRCCS, Università Cattolica, Roma. All data were retrospectively collected and then analysed. All women had a histologically confirmed cervical cancer diagnosis and also subscribed a written informed consent about data collection and their processing for scientific purposes. The Institutional Review Board approved the study (IRB number: DIPUSVSP-03-04-2051). Patients demographics, surgical, pathological, and follow-up data were obtained from an electronic database. Preoperative staging was performed through gynaecologic examination under anesthesia, pelvic ultrasound, and magnetic resonance imaging. All patients with clinical 2009 FIGO stage (Pecorelli et al., 2009) from IA1 with lymphovascular space invasion to IB1/IIA1 with or without suspicious lymph nodes at preoperative imaging assessment were judged eligible for surgery and included in the study. Exclusion criteria were: neoadjuvant therapy prior to the surgery, completion surgery after an incidental diagnosis of cervical cancer following total or sub-total hysterectomy performed for suspicious benign disease and lack of clinical, pathological or surgical data. Patients treated after December 2018 were excluded from the study because our clinical practice changed after "LACC" trial results (Ramirez et al., 2018).

Patients were primarily treated with radical hysterectomy codified according to the QuerleuMorrow classification (Querleu and Morrow, 2008) and systematic pelvic lymphadenectomy or sentinel lymph node biopsy. Aortic lymphadenectomy was performed according to physician discretion and in cases of intraoperatively assessed metastatic disease involving pelvic lymph nodes as shown at frozen section analysis.

All surgical specimens were evaluated by dedicated pathologists. Adjuvant treatment was recommended according to international guidelines (NCCN Cervical Cancer Guidelines, 2019; Cibula et al., 2018).

\section{Assessment of gynaecologic oncology surgeons experience}

The complete learning paths of 11 surgeons were available since all MI-RH procedures for earlystage cervical cancer patients performed during their own careers were traced and recorded. All the 11 surgeons completed their residency in our institution, focusing their training on the field of gynaecologic oncology surgery. Once they became consultants, they performed surgery autonomously. In our institution surgery is generally performed by a consultant as first surgeon, a senior resident as first assistant and a junior resident as second assistant. At least one senior consultant (with more than 10 years of experience as first surgeon) is always available for consultation in case of the less experienced consultant needs.

MI-RH procedures were checked on the basis of the standard guidelines (Cibula et al., 2018). If the surgical data were uncertain or even not complete, the procedures were excluded. Multiple dichotomizations according to the number of MI-RH procedures per GOS were analysed as per survival analyses in order to establish the surgeons 
learning curve in terms of patient prognosis improvement.

\section{Statistical Analysis}

Disease free survival (DFS) was defined as the time elapsed between surgery and recurrence or date of the last follow-up. Overall survival (OS) has been defined as the time elapsed between surgery and death for cervical cancer or date of the last follow up. The $\chi 2$ test or Fisher's exact test for proportion were used to analyse the distribution of clinical and pathological variables between the two groups. Medians and life tables were computed using the product limit estimate by Kaplan-Meier method (Kaplan and Meier, 1958) and the log-rank test was used to assess the statistical significance (Mantel, 1966). Multiple, sequential Cox regression analyses (Cox, 1972) were conducted in order to calculate the hazard ratios (HRs) according to each increase in number of MI-RHs per surgeon, in order to assess the impact of experience on patient survival improvement. The comprehensive GOS learning curve was assessed considering the progressive improvement on patients' survival and described according to the formula: $\sum 10^{\wedge}(1 / \mathrm{HR})$. Cox regression model with stepwise variable selection (Cox, 1972) was used to analyze the impact of experience, based on the number of performed procedures and on the role of different parameters as prognostic factors for DFS. Statistical Package for Social Sciences software version 25.0 (IBM Corporation, Armonk, NY, USA) was adopted to carry out all statistical calculations. For all analyses a $\mathrm{p}$ value $<0.05$ was considered significant.

\section{Results}

From January 1998 to December 2018, 685 consecutive cases of early-stage cervical cancer patients were retrieved from the electronic database. We began to implement the minimally invasive approach in our clinical practice for cervical cancer from 2010 and from 2012 it became the most used. An increase in the rate of patients treated with open surgery was recorded in 2018 (Figure 1). From the whole series of 685 patients, 300 were excluded because they had been managed by the open approach, leaving 385 patients treated with a minimally invasive procedure. Nineteen patients were excluded due to completion surgery after total or subtotal hysterectomy performed for suspicious benign disease, and 3 were excluded due to lack of surgical data, thus leaving 363 cases (Figure 2).

Two hundred and forty-three were treated by surgeons who completed all their learning path in our institution, while 120 were treated by external Consultants.

Main analyses were conducted on these 243 cases with complete pathological and surgical information (Table I).

Median age was 47 years (range 25-80). Most patients underwent type B hysterectomy according to Querleu-Morrow classification. One hundred ninety-six (80.7\%) underwent systematic pelvic lymphadenectomy while 47 (19.3\%) underwent sentinel lymph node biopsy. Aortic lymphadenectomy was performed in $84(34.6 \%)$ cases. The majority of patients had a pathological FIGO stage IB (139,57.2\%), a squamous histotype

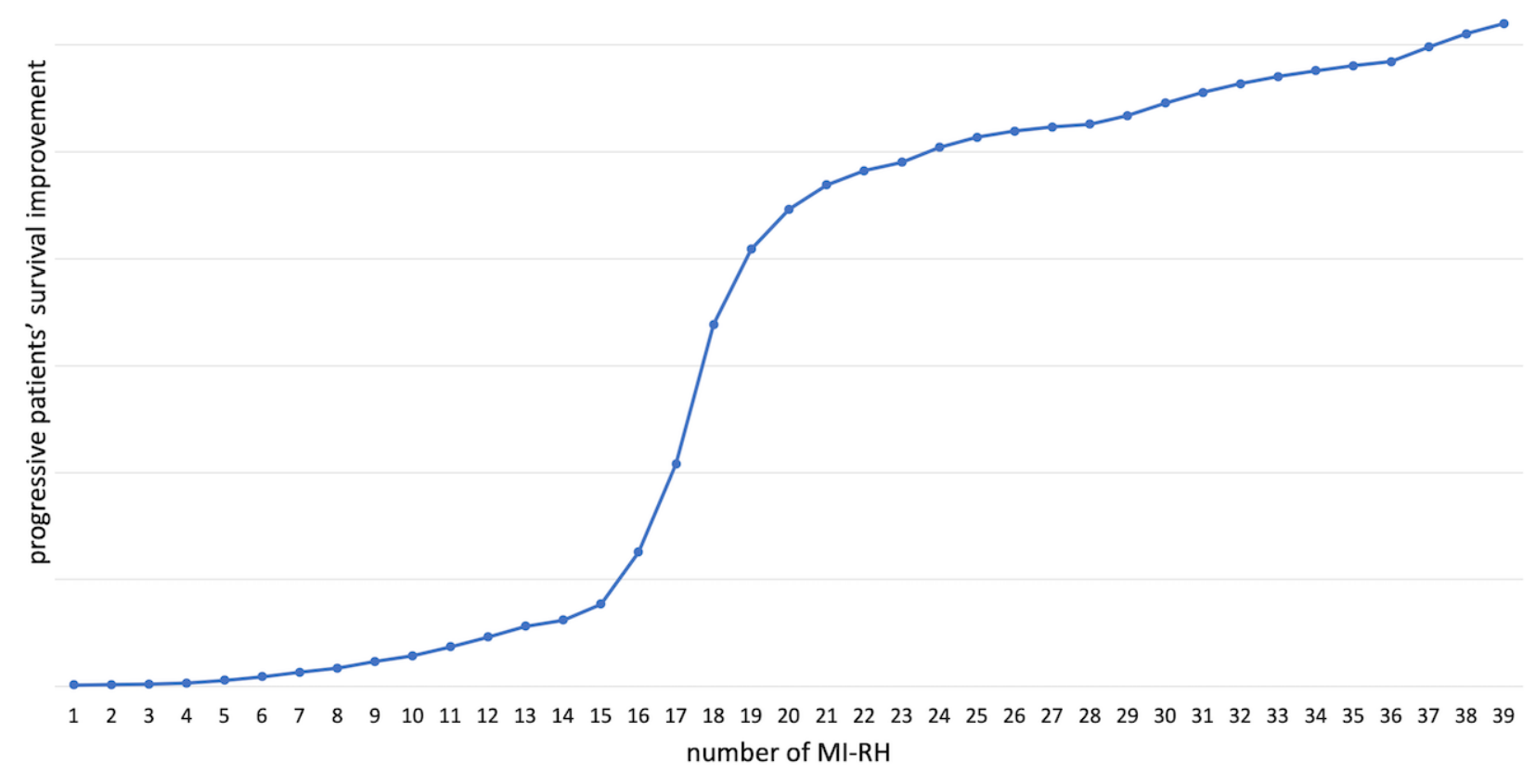

Figure 1: Comprehensive GOS learning curve - Trend of the learning curve was calculated considering the cumulative sum of progressive improvement on patients' survival according to the increase of number performed by a GOS during his/her career. 


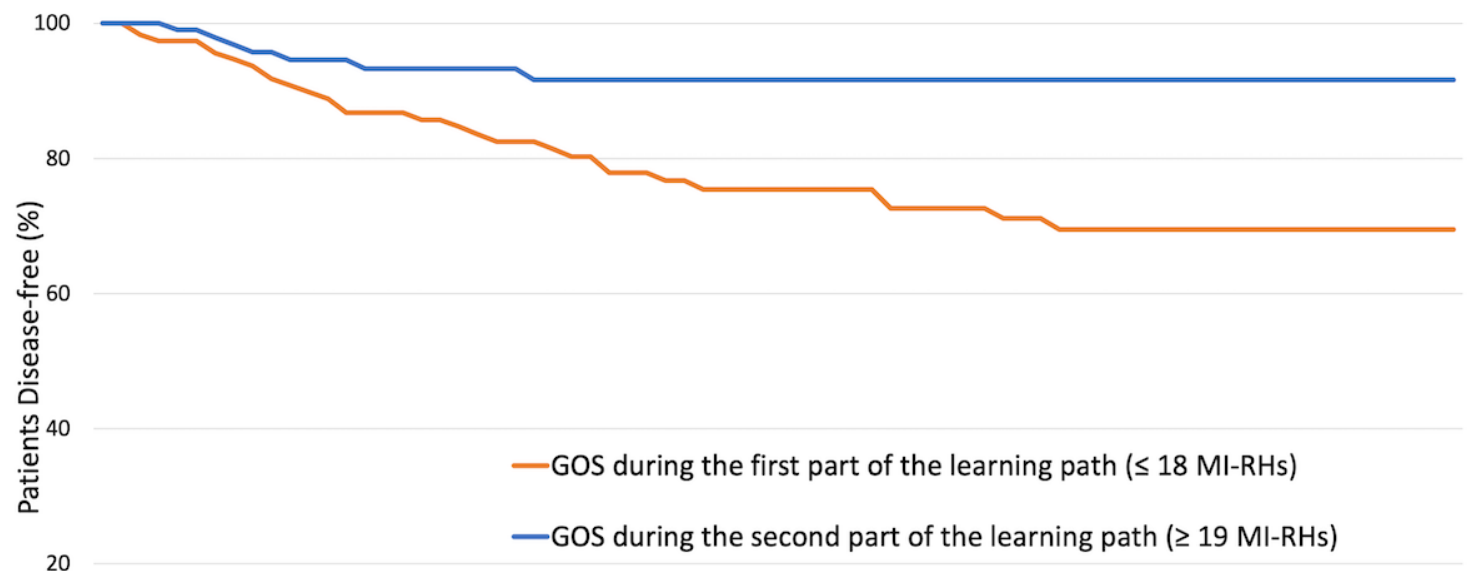

Log rank test $p$ value $\mathbf{= 0 . 0 0 5}$

\begin{tabular}{|c|c|c|c|c|c|c|c|}
\hline & 0 & 12 & 24 & $\begin{array}{l}36 \\
\text { Months }\end{array}$ & 48 & 60 & 72 \\
\hline \multicolumn{8}{|c|}{ Number at risk } \\
\hline$\leq 18 \mathrm{Ml}-\mathrm{RHs}$ & 128 & 109 & 82 & 73 & 64 & 40 & 23 \\
\hline$\geq 19 \mathrm{Ml}-\mathrm{RHS}$ & 115 & 88 & 66 & 53 & 25 & 9 & 1 \\
\hline
\end{tabular}

Figure 2: Disease-free survival curve according to GOS experience.

$(157,64.6 \%)$ and a tumor diameter $<2 \mathrm{~cm}(157$, $64.6 \%$ ). Adjuvant therapy was performed in 103 (42.3\%) cases.

As of September 2019, the median follow-up was 38 months (range: 3-111); 35 (14.4\%) patients relapsed and $11(4.5 \%)$ died from disease.

Surgeons learning path was retraced classifying patients according to the progressive number of MI-RH for early-stage cervical cancer performed by each GOS (i.e. the first patients operated by each surgeon were classified with number 1 , the second were classified with number 2 and so on).

Not all surgeons started their career as first operator at the same time and 6 of them became Consultants after 2010.

The 11 surgeons included in the analysis performed a median of 17 MI-RHs for early-stage cervical cancer (range: 6-47). Four of them (36.3\%) performed more than 30 procedures as first surgeon. The mean number of MI-RHs performed for earlystage cervical cancer per year by each surgeon was 6.2 (range: $2.8-7.1$ ).

Multiple, sequential survival analyses were conducted according to the number of MI-RHs per GOS in order to assess the impact of experience on patient survival improvement (Figure 3). Excluding the range of the first 4 procedures, each unitary increment in MI-RHs performed by a surgeon provided a reduction of patients' risk of recurrence (hazard ratio: from 0.974 to 0.321 ).

In particular, the experience, measured by evaluating the number of performed procedures, showed a statistically significant impact on patients' prognosis starting from the 14th MI-RH performed (hazard ratio: 0.499 ; $95 \% \mathrm{CI}: 0.251-0.992$; $\mathrm{p}$ value $=$ 0.048). This statistical significance lasted until the 21st MI-RH performed (hazard ratio: $0.424 ; 95 \% \mathrm{CI}$ : $0.185-0.974 ; \mathrm{p}$ value $=0.043$ ). The peak of reduction of the recurrence risk was shown when the surgeon performed the 19th MI-RH (hazard ratio: 0.321; 95\%CI: 0.140-0.737; p value $=0.007)$. Data details are shown in Table II.

The comprehensive GOS learning curve showed only a tiny impact of the experience on patients' prognosis during the first procedures (Figure 1). A substantial and steep improvement of patients DFS was shown between the $14^{\text {th }}$ and the $21^{\text {st }}$ performed MI-RHs. Subsequently, as the number of performed MI-RHs increased, a stable, small effect on the patient prognosis was observed.

According to these results, patients were divided in two groups regarding the operators experience at the time of surgery. The first one included patients managed by a gynaecologic oncologist at the beginning of the learning path in MI-RH for earlystage cervical cancer $(<18$ procedure performed), while the other group included patients treated by a physician who gained enough experience ( $>19 \mathrm{MI}-$ RH performed).

There was no difference between the two groups according to the main pathological risk factors and the adjuvant treatment administered (Table III).

The survival outcomes of patients treated by a gynaecologic oncologist once he/she had gained experience in MI-RH were significantly better than those of patients treated at the beginning of the learning path (3-years DFS: $91.6 \%$ vs $75.4 \%$ respectively, $p=0.005$, Figure 2 ). Between the 
Table I. - Surgical and clinical-pathological characteristics of the series.

\begin{tabular}{|l|c|}
\hline Characteristics & N. (\%) \\
\hline Patients & 243 \\
\hline Median Age, yrs (range) & $47(25-80)$ \\
\hline Radicality of Surgery & \\
- Type A & $43(17.7)$ \\
- Type B & $111(45.7)$ \\
- Type C & $89(36.6)$ \\
\hline Lymph Node Surgery & \\
- Sentinel Lymph Node Biopsy & $47(19.3)$ \\
- Pelvic Lymphadenectomy & $196(80.7)$ \\
\hline Aortic Lymphadenectomy & \\
- No & $159(65.4)$ \\
- Yes & $84(34.6)$ \\
\hline Pathological FIGO stage & \\
- IA1 & $52(21.4)$ \\
- IA2 & $15(6.2)$ \\
- IB1 & $131(53.9)$ \\
- IB2 & $8(3.3)$ \\
- IIA1 & $9(3.7)$ \\
- IIA2 & $5(2.1)$ \\
- IIB & $23(9.5)$ \\
\hline Histology & \\
- Squamous carcinoma & $140(57.6)$ \\
- Other & $157(64.6)$ \\
\hline Grading & $86(35.4)$ \\
- G1 / G2 & $178(73)$ \\
- G3 & $53(21.8)$ \\
\hline Tumor diameter & $157(64.6)$ \\
- - 20 mm & $86(35.4)$ \\
- > 20 mm & \\
\hline Lymphovascular space invasion & \\
- Absent & \\
- Present & \\
\hline Lymph node status & $(63.4)$ \\
- Negative & \\
- Positive & \\
\hline Adjuvant therapy & \\
- No & \\
- Radiotherapy & \\
- Chemotherapy & - concomitant chemoradiotherapy \\
\hline according to Querleu and Morrow classifications \\
\hline
\end{tabular}

two periods of the learning curve there was a nonstatistically significant difference in terms of patient OS (3-years OS: $96.7 \%$ vs 91.3\%respectively, $\mathrm{p}=0.121$, data not shown).

Univariate analyses showed that GOS practice in MI-RH was significantly associated to patient DFS. Multivariate analyses confirmed that the GOS experience resulted as an independent factor on patient prognosis (Table IV).

A supplementary analysis conducted on the 171 patients managed by the laparoscopic approach only confirmed that a gynaecologic oncologist significantly influences patients prognosis according to the level of experience (3- years DFS of "GOS during the first part of the learning path" vs. "GOS during the second part of the learning path": $93.4 \%$ vs $75.5 \%, p=0.013$, Figure 4 ).

Figure 5 shows that the GOS learning curve had a relatively relevance in cases with $<2 \mathrm{~cm}$ tumor size (3- years DFS of "GOS during the first part of the learning path" vs. "GOS during the second part of the learning path": $94.2 \%$ vs $87.6 \%$, p value $=0.209$ ). On the other hand, the GOS experience was statistically relevant when the tumor dimension was $>2 \mathrm{~cm}$ (3-years DFS of "GOS during the first part of the learning path" vs. "GOS during the second part of the learning path": $86.4 \%$ vs $56.8 \%$, p=0.017).

\section{Discussion}

This study demonstrates that there is a strict relationship between GOS experience and earlystage cervical cancer patient prognosis based on the number of MI-RH procedures and that it is independent of other, well known, prognostic factors of cervical cancer (Fagotti et al., 2016; Wagner et al., 2013; Pedone Anchora et al., 2020a). In the vast majority of previous studies concerning the learning curve of surgeons, their experience has been evaluated in terms of peri-operative outcomes according to the absolute number of radical hysterectomies (Yim et al., 2013; Madhuri et al., 2021; Hwang et al., 2012; Oyama et al., 2019; Chong et al., 2009; Cusimano et al., 2019; Liu et al., 2019).

The present analysis showed that the increase of GOS experience allowed better results in terms of oncological outcomes. Furthermore, surgeon experience affected patient prognosis following the typical trend of a learning curve. At the beginning, a steady recurrence-risk reduction trend was associated with the increase of number of MI-RHs performed. Subsequently, there was a phase of steep growth of the curve. This could be considered the most significant period of the learning process since each procedure performed improves the surgeon outcomes and has a strong impact on the patient prognosis. Lastly, once a surgeon achieved a certain level of experience, further practice gave only a small and stable improvement on patient survival.

In addition, we showed that the survival related results in the laparoscopic group were in accordance with the primary analysis. On the other hand, the sample of patients treated with the robotic approach was too small to draw any relevant conclusion (data not shown). The experience appeared as having a greater impact among high-risk cases, 
Table II. - Cox regression analyses association between GOS experience, defined by sequential dichotomizations of the number of MI-RS performed by the GOS, and disease-free survival.

\begin{tabular}{|c|c|c|c|}
\hline $\begin{array}{c}\text { Number of MI-RH } \\
\text { performed }\end{array}$ & Hazard Ratio & $95 \% \mathrm{CI}^{*}$ & $\mathrm{p}$ value \\
\hline$\leq 1$ vs $\geq 2$ & 0.891 & $0.215-3.373$ & 0.880 \\
\hline$\leq 2 \mathrm{vs} \geq 3$ & 1.968 & $0.472-8.202$ & 0.353 \\
\hline$\leq 3 \mathrm{vs} \geq 4$ & 1.439 & $0.508-4.078$ & 0.494 \\
\hline$\leq 4 \mathrm{vs} \geq 5$ & 0.974 & $0.425-2.231$ & 0.950 \\
\hline$\leq 5 \mathrm{vs} \geq 6$ & 0.705 & $0.338-1.468$ & 0.350 \\
\hline$\leq 6 \mathrm{vs} \geq 7$ & 0.665 & $0.331-1.337$ & 0.252 \\
\hline$\leq 7 \mathrm{vs} \geq 8$ & 0.615 & $0.312-1.211$ & 0.160 \\
\hline$\leq 8$ vs $\geq 9$ & 0.632 & $0.323-1.236$ & 0.180 \\
\hline$\leq 9 \mathrm{vs} \geq 10$ & 0.558 & $0.287-1.085$ & 0.086 \\
\hline$\leq 10 \mathrm{vs} \geq 11$ & 0.581 & $0.299-1.130$ & 0.110 \\
\hline$\leq 11$ vs $\geq 12$ & 0.518 & $0.265-1.012$ & 0.054 \\
\hline$\leq 12$ vs $\geq 13$ & 0.511 & $0.260-1.007$ & 0.052 \\
\hline$\leq 13 \mathrm{vs} \geq 14$ & 0.499 & $0.251-0.992$ & 0.048 \\
\hline$\leq 14$ vs $\geq 15$ & 0.568 & $0.286-1.131$ & 0.107 \\
\hline$\leq 15 \mathrm{vs} \geq 16$ & 0.460 & $0.225-0.941$ & 0.033 \\
\hline$\leq 16 \mathrm{vs} \geq 17$ & 0.372 & $0.174-0.796$ & 0.011 \\
\hline$\leq 17 \mathrm{vs} \geq 18$ & 0.343 & $0.156-0.756$ & 0.008 \\
\hline$\leq 18$ vs $\geq 19$ & 0.321 & $0.140-0.737$ & 0.007 \\
\hline$\leq 19$ vs $\geq 20$ & 0.351 & $0.153-0.805$ & 0.013 \\
\hline$\leq 20$ vs $\geq 21$ & 0.389 & $0.169-0.893$ & 0.026 \\
\hline$\leq 21$ vs $\geq 22$ & 0.424 & $0.185-0.974$ & 0.043 \\
\hline$\leq 22$ vs $\geq 23$ & 0.471 & $0.205-1.083$ & 0.076 \\
\hline$\leq 23$ vs $\geq 24$ & 0.526 & $0.229-1.210$ & 0.131 \\
\hline$\leq 24$ vs $\geq 25$ & 0.466 & $0.193-1.128$ & 0.090 \\
\hline$\leq 26$ vs $\geq 27$ & 0.508 & $0.210-1.231$ & 0.134 \\
\hline$\leq 26$ vs $\geq 27$ & 0.567 & $0.234-1.375$ & 0.210 \\
\hline$\leq 27 \mathrm{vs} \geq 28$ & 0.634 & $0.262-1.538$ & 0.314 \\
\hline$\leq 28$ vs $\geq 29$ & 0.697 & $0.287-1691$ & 0.425 \\
\hline$\leq 29$ vs $\geq 30$ & 0.528 & $0.310-1.823$ & 0.528 \\
\hline$\leq 30 \mathrm{vs} \geq 31$ & 0.481 & $0.169-1.368$ & 0.170 \\
\hline$\leq 31$ vs $\geq 32$ & 0.502 & $0.176-1.1430$ & 0.197 \\
\hline$\leq 32$ vs $\geq 33$ & 0.524 & $0.184-1.495$ & 0.227 \\
\hline$\leq 33$ vs $\geq 34$ & 0.547 & $0.192-1.562$ & 0.260 \\
\hline$\leq 34$ vs $\geq 35$ & 0.573 & $0.201-1.639$ & 0.299 \\
\hline$\leq 35$ vs $\geq 36$ & 0.602 & $0.210-1.723$ & 0.344 \\
\hline$\leq 36 \mathrm{vs} \geq 37$ & 0.633 & $0.221-1.814$ & 0.633 \\
\hline$\leq 37 \mathrm{vs} \geq 38$ & 0.468 & $0.142-1.542$ & 0.212 \\
\hline$\leq 38$ vs $\geq 39$ & 0.479 & $0.145-1.581$ & 0.227 \\
\hline$\leq 39 \mathrm{vs} \geq 40$ & 0.503 & $0.152-1.659$ & 0.259 \\
\hline \multicolumn{4}{|c|}{ Bold values indicate statistically significant; ${ }^{*} \mathrm{CI}$ : confidence interval } \\
\hline
\end{tabular}

since the difference between the different phases of a learning curve was significant especially in cases of tumor $>2 \mathrm{~cm}$.

In our series the peak of recurrence risk reduction was represented by 19th MI-RHs. One could argue that the identified cut-off could not be generalised to other series due to the limitations inherent to a retrospective study (i.e.selection bias, missing data/variables, etc.), and even to a single-centre patient series. We had planned at the beginning to exclude in the present analysis other institutions because the homogeneity of surgical procedures, 
Table III. - Clinical-pathological characteristics of patients grouped according to GOS experience at the time of their surgery.

\begin{tabular}{|c|c|c|c|}
\hline & $\begin{array}{l}\text { GOS during the } \\
\text { first part of the } \\
\text { learning path } \\
(\leq 18 \text { MI-RH) }\end{array}$ & $\begin{array}{l}\text { GOS during } \\
\text { the second } \\
\text { part of the } \\
\text { learning path } \\
\text { ( } \geq 19 \text { MI-RH) }\end{array}$ & \\
\hline Characteristics & N. $(\%)$ & N. (\%) & $\mathrm{p}$ Value \\
\hline Patients & 128 & 115 & \\
\hline $\begin{array}{l}\text { Pathological FIGO stage } \\
\text { - IA1 } \\
\text { - IA2 } \\
\text { - IB1 } \\
\text { - IB2 } \\
\text { - IIA1 } \\
\text { - IIA2 } \\
\text { - IIB }\end{array}$ & $\begin{array}{c}31(24.2) \\
11(8.6) \\
65(50.8) \\
2(1.6) \\
3(2.3) \\
4(3.1) \\
12(9.4)\end{array}$ & $\begin{array}{c}21(18.3) \\
4(3.5) \\
66(57.4) \\
6(5.2) \\
6(5.2) \\
1(0.9) \\
11(9.6)\end{array}$ & 0.154 \\
\hline $\begin{array}{l}\text { Histology } \\
\text { - Squamous carcinoma } \\
\text { - Other }\end{array}$ & $\begin{array}{l}86(67.2) \\
42(32.8)\end{array}$ & $\begin{array}{l}71(61.7) \\
44(38.3)\end{array}$ & 0.375 \\
\hline $\begin{array}{l}\text { Grading } \\
\text { - G1 / G2 } \\
\text { - G3 }\end{array}$ & $\begin{array}{l}97(75.8) \\
31(24.2)\end{array}$ & $\begin{array}{l}90(78.3) \\
25(21.7)\end{array}$ & 0.678 \\
\hline $\begin{array}{l}\text { Tumor diameter } \\
-\leq 20 \mathrm{~mm} \\
->20 \mathrm{~mm}\end{array}$ & $\begin{array}{l}86(67.2) \\
42(32.8)\end{array}$ & $\begin{array}{l}73(63.5) \\
42(36.5)\end{array}$ & 0.540 \\
\hline $\begin{array}{l}\text { Lymphovascular space invasion } \\
\text { - Absent } \\
\text { - Present }\end{array}$ & $\begin{array}{l}79(61.7) \\
49(38.3)\end{array}$ & $\begin{array}{l}75(65.2) \\
40(34.8)\end{array}$ & 0.850 \\
\hline $\begin{array}{l}\text { Lymph node status } \\
\text { - Negative } \\
\text { - Positive }\end{array}$ & $\begin{array}{c}102(79.7) \\
26(20.3)\end{array}$ & $\begin{array}{l}96(83.5) \\
19(16.5)\end{array}$ & 0.448 \\
\hline $\begin{array}{l}\text { Adjuvant therapy } \\
\text { - No } \\
\text { - Radiotherapy } \\
\text { - Chemotherapy } \\
\text { - concomitant chemoradiotherapy }\end{array}$ & $\begin{aligned} 77 & (60.2) \\
28 & (21.9) \\
2 & (1.6) \\
21 & (16.4)\end{aligned}$ & $\begin{array}{c}66(57.4) \\
15(13.0) \\
2(1.7) \\
32(27.8)\end{array}$ & 0.171 \\
\hline
\end{tabular}

equipment/facilities and the standardised selection criteria for recruitment shared by all surgeons could be better guaranteed by a single-institution series.

As far as the identified cut-off, we acknowledge that the absolute number of performed procedures without the referral to a specific time interval could have introduced a bias in the evaluation of the surgeon skillfulness. However, although we could have had details relative, for instance, to the number of MI-RHs performed by per month, this ratio would have not been sufficiently reliable given the heterogeneity of time frames and modalities of individual learning path.

Moreover, in the present series, we failed to identify a significant difference in terms of OS according to surgeon learning path. However, one could consider that, while DFS could be strictly related to basic treatment and pathological tumor features, the OS may also be influenced by other factors such as the site (Quinn et al., 2006; Boussios et al., 2016) and management of recurrence (Dornhöfer and Höckel, 2008; Gadducci et al., 2010; Vizzielli et al., 2017; Suzuki et al., 2019).

Present findings should be evaluated in the current clinical context. After publication of the LACC trial, some international guidelines and statements of the Scientific Societies generally accept and recommend implementing the trial evidence in clinical practice (NCCN Cervical Cancer Guidelines, 2019; Hillemanns et al., 2019) while others suggest considering its results along with those of other publications (Querleu et al., 2020, Yim et al. 2019). Despite different opinions and statements from experts and Societies, all of them stress the importance of providing accurate 
Table IV. - Cox's regression uni- and multi-variate analyses of pathologic and surgical parameters associated to disease-free survival.

\begin{tabular}{|l|c|c|c|c|}
\hline \multirow{2}{*}{} & \multicolumn{2}{|c|}{ Univariate Analysis } & \multicolumn{2}{c|}{ Multivariate Analysis } \\
\hline Characteristics & HR $(95 \%$ CI $) *$ & p Value & $\beta$ & $\mathrm{p}$ Value \\
\hline Pathological FIGO stage & $1.444(1.004-2.078)$ & 0.048 & $/$ & 0.651 \\
\hline Histology & $1.075(0.534-2.162)$ & 0.840 & $/$ & $/$ \\
\hline Grading & $1.402(0.687-2.863)$ & 0.354 & $/$ & $/$ \\
\hline Tumor diameter & $4.164(2.055-8.438)$ & 0.001 & 1.356 & 0.001 \\
\hline Lymphovascular space invasion & $1.560(1.199-2.030)$ & 0.002 & $/$ & 0.120 \\
\hline Lymph nodal status & $1.267(1.003-2.268)$ & 0.047 & $/$ & 0.202 \\
\hline GOS experience $(\leq 18$ vs $\geq 19$ MI-RH) & $0.321(0.140-0.737)$ & 0.007 & -1.013 & 0.018 \\
\hline * HR: Hazzard Ratio, CI: confidence interval; Bold values indicate statistically significant & \\
\hline
\end{tabular}

counseling to patients regarding advantages and disadvantages along with all factors that could influence outcomes of each surgical approach.

Literature is constantly enriched with studies comparing MIS to open surgery for early-stage cervical cancer (Brandt et al., 2020) also in specific subgroups (Pedone Anchora et al., 2020b) and with research that investigates possible explanation of LACC trial results (Casarin et al., 2020). This is not the topic of the present study. The concept that not all surgeons who perform MI-RH have similar oncological outcomes should be taken into account in future studies comparing open and minimally invasive surgery for early-stage cervical cancer (NCT03739944, NCT03719547).

Recently, the European Society of Gynecological Oncology Group developed quality indicators for surgical treatment of cervical cancer (Cibula et al., 2020). It is recommended that patients are treated in high-volume centres with specialised surgeons. Present findings underline that not all the surgeons in a high-volume hospital have the same proficiency in all settings and that the minimally invasive treatment for early-stage cervical cancer requires a very specific training.

The main conclusion of the present study is that the experience that a gynaecologic oncologist can achieve by practice in MI-RH is an independent prognostic factor for early-stage cervical cancer patients.

Although other non-measurable data, such as the individual comprehensive surgical skill and the competence regarding the disease, the pelvic anatomy etc., may influence the GOS skillfulness, a disease-specific training under the supervision of an expert surgeon should be required prior to perform MI-RH safely in cases of early-stage cervical cancer.

A prospective trial is advisable to confirm our findings and we strongly believe that these results could encourage Scientific Societies to define better the minimum level of training required for gynaecologic oncologic surgeons, not only in the field of early-stage cervical cancer, in order to provide high, standardised care to our patients.

\section{References}

Bansal N, Herzog TJ, Shaw RE et al. Primary therapy for earlystage cervical cancer: radical hysterectomy vs radiation. Am J Obs Gynecol. 2009;201:485.e1-9.

Barletta F, Corrado G, Vizza E. Laparoscopic radical hysterectomy with the use of SNAIL Tenaculum ${ }^{\mathrm{TM}}$. A simplified uterine manipulator for the management of early cervical cancer. It J Gynaecol Obstet. 2015;27:N.1.

Boussios S, Seraj E, Zarkavelis G et al. Management of patients with recurrent/advanced cervical cancer beyond first line platinum regimens: Where do we stand? A literature review. Crit Rev Oncol Hematol. 2016;108:164-74.

Brandt B, Sioulas V, Basaran D et al. Minimally invasive surgery versus laparotomy for radical hysterectomy in the management of early-stage cervical cancer: Survival outcomes. Gynecol Oncol. 2020;156:591-597.

Cao T, Feng Y, Huang Q et al. Prognostic and safety roles in laparoscopic versus abdominal radical hysterectomy in cervical cancer: A meta-analysis. J Laparoendosc Adv Surg Tech A. 2015;25:990-8.

Casarin J, Buda A, Bogani G et al. Predictors of recurrence following laparoscopic radical hysterectomy for earlystage cervical cancer: A multi-institutional study. Gynecol Oncol. 2020;159:164-70.

Chong GO, Park NY, Hong DG et al. Learning curve of laparoscopic radical hysterectomy with pelvic and/or paraaortic lymphadenectomy in the early and locally advanced cervical cancer: comparison of the first 50 and second 50 cases. Int J Gynecol Cancer. 2009;19:1459-64.

Cibula D, Planchamp F, Fischerova D et al. European Society of gynaecological oncology quality indicators for surgical treatment ofcervical cancer. Int J Gynecol Cancer. 2020;30:3-14.

Cibula D, Pötter R, Planchamp F et al. The European Society of Gynaecological Oncology/European Society for Radiotherapy and Oncology/European Society of Pathology Guidelines for the Management of Patients With Cervical Cancer. Int J Gynecol Cancer. 2018;28:641-55.

Corrado G, Vizza E, Legge F, et al. Comparison of different surgical approaches for stage IB1 cervical cancer patients: a multi-institution study and a review of the literature. Int $\mathrm{J}$ Gynecol Cancer. 2018;28:1020-8. 
Cox DR. Models and Life-Tables Regression. J R Stat Soc Ser B (Methodological). 1972;34:187-220.

Cusimano MC, Baxter NN, Gien LT et al. Impact of surgical approach on oncologic outcomes in women undergoing radical hysterectomy for cervical cancer. Am J Obstet Gynecol. 2019;221:619.e1-619.e24.

Diver E, Hinchcliff E, Gockley A, et al. Minimally invasive radical hysterectomy for cervical cancer is associated with reduced morbidity and similar survival outcomes compared with laparotomy. J Minim Invasive Gynecol. 2017;24:4026 .

Dornhöfer N, Höckel M. New developments in the surgical therapy of cervical carcinoma. Ann N Y Acad Sci. 2008;1138:233-52.

Fagotti A, Pedone Anchora L, Conte C, et al. Beyond sentinel node algorithm. Toward a more tailored surgery for cervical cancer patients. Cancer Med. 2016;5:1725-30.

Gadducci A, Tana R, Cosio S et al. Treatment options in recurrent cervical cancer (Review). Oncol Lett. 2010;1:3-11.

Gallotta V, Conte C, Federico A et al. Robotic versus laparoscopic radical hysterectomy in early cervical cancer: A case matched control study. Eur J Surg Oncol. 2018;44:754-59.

Hillemanns P, Brucker S, Holthaus B et al. Updated opinion of the uterus commission of the Gynecological Oncology Working Group (AGO) and the Gynecological Endoscopy Working Group (AGE) of the German Society of Gynecology and Obstetrics (DGGG) on the randomized study comparing minimally invasive with abdominal radical hysterectomy for early-stage cervical cancer (LACC). Geburtshilfe Frauenheilkd. 2019:79:145-7.

Hwang JH, Yoo HJ, Joo J et al. Learning curve analysis of laparoscopic radical hysterectomy and lymph node dissection in early cervical cancer. Eur J Obstet Gynecol Reprod Biol. 2012;163:219-23.

Kaplan EL, Meier P. Nonparametric estimation from incomplete samples. J Am Stat Assoc. 1958;53:457- 81.

Kimmig R, Ind T. Minimally invasive surgery for cervical cancer: consequences for treatment after LACC Study. J Gynecol Oncol. 2018;29:e75.

Laterza RM, Uccella S, Casarin J et al. Recurrence of early stage cervical cancer after laparoscopic versus open radical surgery. Int J Gynecol Cancer. 2016;26:47-52.

Lee EJ, Kang H, Kim DH. A comparative study of laparoscopic radical hysterectomy with radical abdominal hysterectomy for early-stage cervical cancer: a long-term follow-up study. Eur J Obstet Gynecol Reprod Biol 2011;156:83-6.

Leitao MM Jr. The LACC Trial: Has minimally invasive surgery for early-stage cervical cancer been dealt a knockout punch? Int J Gynecol Cancer. 2018;28:1248-50.

Liu Y, Li L, Wu M et al. The impact of the surgical routes and learning curve of radical hysterectomy on the survival outcomes instageIB cervical cancer: A retrospective cohort study. Int J Surg. 2019;68:72-7.

Madhuri TK, Hamzawala I, Tailor A et al. Robot assisted surgery in gynaecologic oncology-starting a program and initial learning curve from a UK tertiary referral centre: the Guildford perspective. Int J Med Robot. 2012;8:496-503.

Mantel N. Evaluation of survival data and two new rank order statistics arising in its consideration. Cancer Chemother Rep. 1966;50:163-70.

Nam JH, Park JY, Kim DY et al. Laparoscopic versus open radical hysterectomy in early-stage cervical cancer: longterm survival outcomes in a matched cohort study. Ann Oncol. 2012;23:903-11.
National Comprehensive Cancer Network (NCCN) Cervical Cancer Guidelines. Cervical Cancer. 2019. https://www. nccn.org/professionals/physician_gls/pdf/cervical.pdf

Nezhat FR, Ananth CV, Vintzileos AM. The two Achilles heels of surgical randomized controlled trials: differences in surgical skills and reporting of average performance. Am J Obstet Gynecol. 2019;221:230-32.

Oyama K, Kanno K, Kojima R et al. Short-term outcomes of robotic-assisted versus conventional laparoscopic radical hysterectomy for early-stage cervical cancer: A singlecenter study. J Obstet Gynaecol Res. 2019;45:405-11.

Park DA, Yun JE, Kim SW et al. Surgical and clinical safety and effectiveness of robot-assisted laparoscopic hysterectomy compared to conventional laparoscopy and laparotomy for cervical cancer: A systematic review and meta-analysis. Eur J Surg Oncol. 2017;43:994-1002.

Pecorelli S, Zigliani L, Odicino F. Revised FIGO staging for carcinoma of the cervix. Int J Gynaecol Obs. 2009;105:1078.

Pedone Anchora L, Carbone V, Gallotta V et al. Should the number of metastatic pelvic lymph nodes be integrated into the 2018 Figo Staging Classification of Early Stage Cervical Cancer?. Cancers (Basel). 2020a;12:1552.

Pedone Anchora L, Turco LC, Bizzarri N et al. How to select early-stage cervical cancer patients still suitable for laparoscopic radical hysterectomy: a propensity-matched study. Ann Surg Oncol. 2020b;27:1947-55.

Querleu D, Cibula D, Concin N et al. Laparoscopic radical hysterectomy: a European Society of Gynaecological Oncology (ESGO) statement. Int J Gynecol Cancer. 2020;30:15.

Querleu D, Morrow CP. Classification of radical hysterectomy. Lancet Oncol. 2008;9:297-303.

Quinn MA, BenedetJL, Odicino F, et al. Carcinoma of the cervix uteri. FIGO 26th Annual Report on the results of treatment in gynecological cancer. Int J Gynaecol Obstet. 2006;95:43-103.

Ramirez PT, Frumovitz M, Pareja R et al. Minimally invasive versus abdominal radical hysterectomy for cervical cancer. N Eng J Med. 2018;379:1895-904

Suzuki K, Nagao S, Shibutani T et al. Phase II trial of paclitaxel, carboplatin, and bevacizumab for advanced or recurrent cervical cancer. Gynecol Oncol. 2019;154:554-57.

Vergote I, Magrina JF, Zanagnolo V et al. The LACC trial and minimally invasive surgery in cervical cancer. J Minim Invasive Gynecol. 2020;27:462-63.

Vizzielli G, Chiantera V, Tinelli G, et al. Out-of-the-box pelvic surgery including iliopsoas resection for recurrent gynecological malignancies: Does that make sense? A single-institution case-series. Eur J Surg Oncol. 2017;43:710-16.

Wagner AE, Pappas L, Ghia AJ et al. Impact of tumor size on survival in cancer of the cervix and validation of stage IIA 1 and IIA2 subdivisions. Gynecol Oncol. 2013;129:517-21.

Wang Y, Deng L, Cao L et al. The outcome of laparoscopy versus laparotomy for the management of early stage cervical cancer-meta analysis. J Minim Invasive Gynecol. 2015;22:4-5.

Yim GW, Kim SW, Nam EJ, et al. Learning curve analysis of robot-assisted radical hysterectomy for cervical cancer: initial experience at a single institution. J Gynecol Oncol. 2013;24:303-12.

Yim GW, Suh DH, Kim JW et al. The 34th Annual Meeting of the Korean Society of Gynecologic Oncology 2019: meeting report. J Gynecol Oncol. 2019;30:91. 
Supplementary figures

EARLY STAGE CERVICAL CANCER PATIENTS

(January 1998-December 2018)

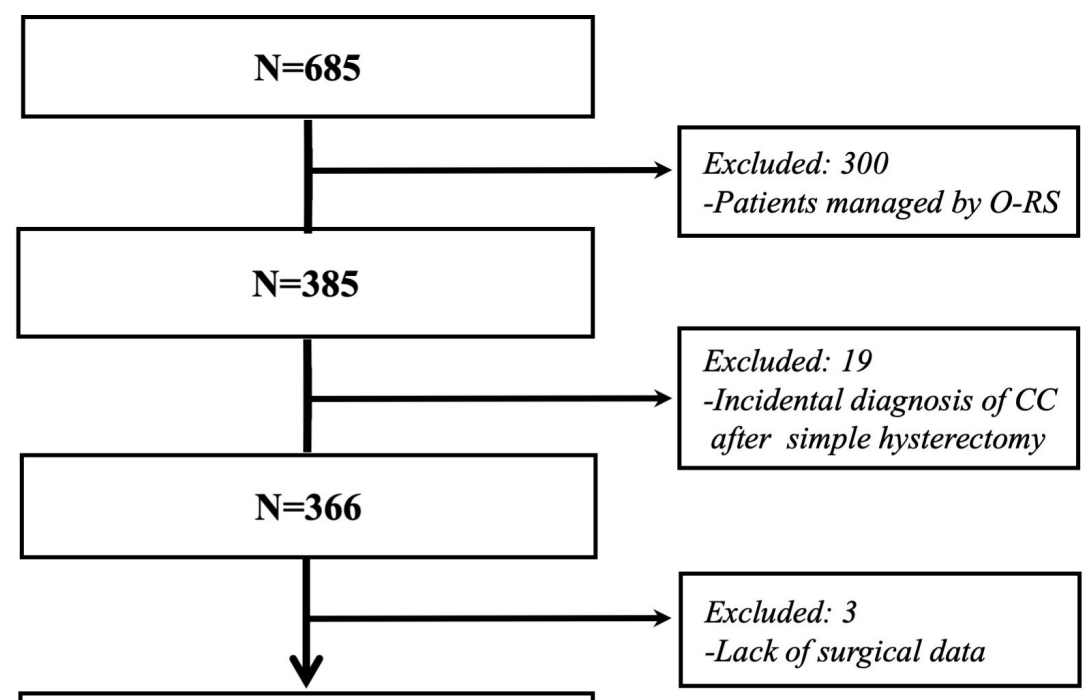

PATIENTS AVAILABLE FOR THE ANALYSIS

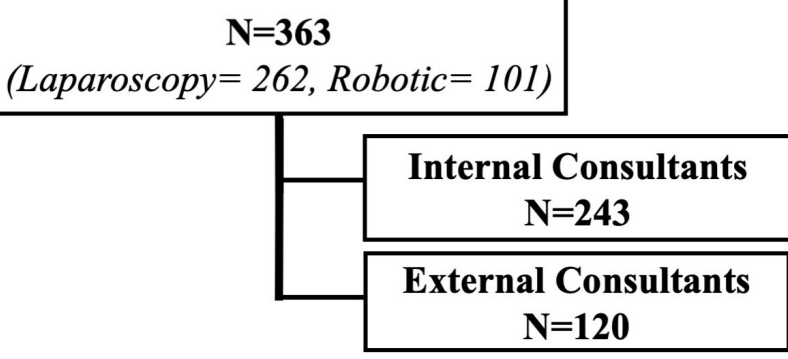

Supplementary figure 1: Study population.

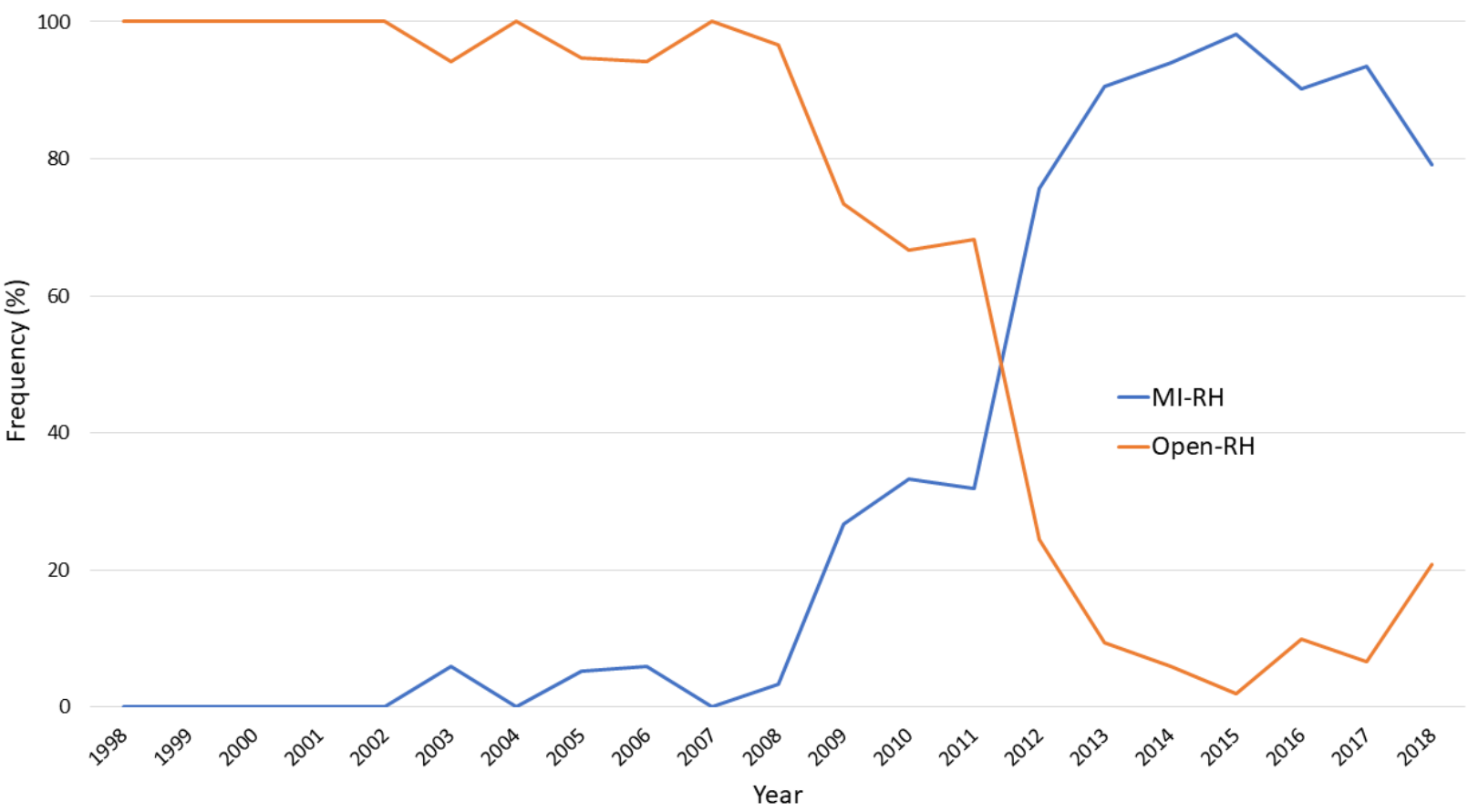

Supplementary figure 2: Frequency of open and minimally invasive radical hysterectomy performed per year. 


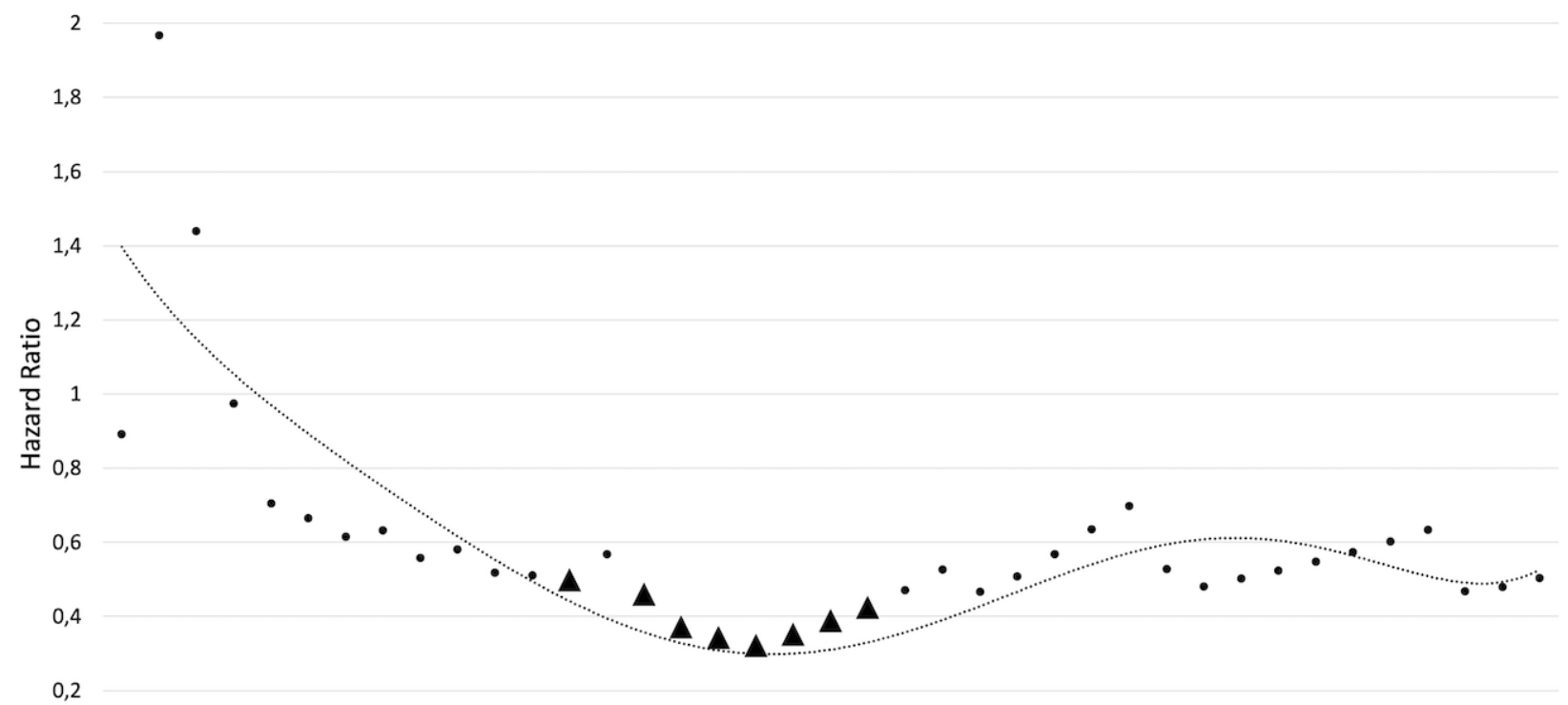

0

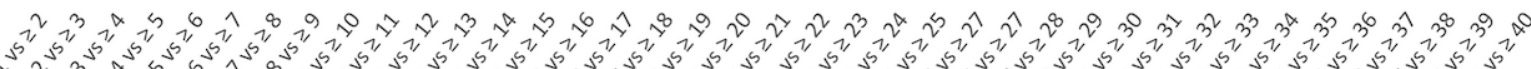

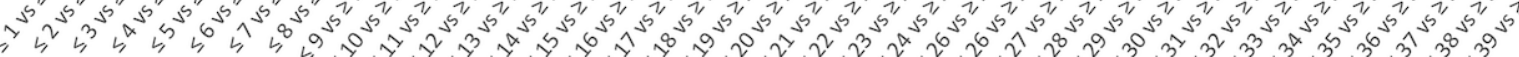

Supplementary figure 3: Scatter plot. - Scatter plot of multiple survival regression analyses. Axis of ordinates shows Hazard Ratios and abscissa the comparison groups of analyses. Triangle points indicate statistically significant. Dashed line represented polynomial trendline.

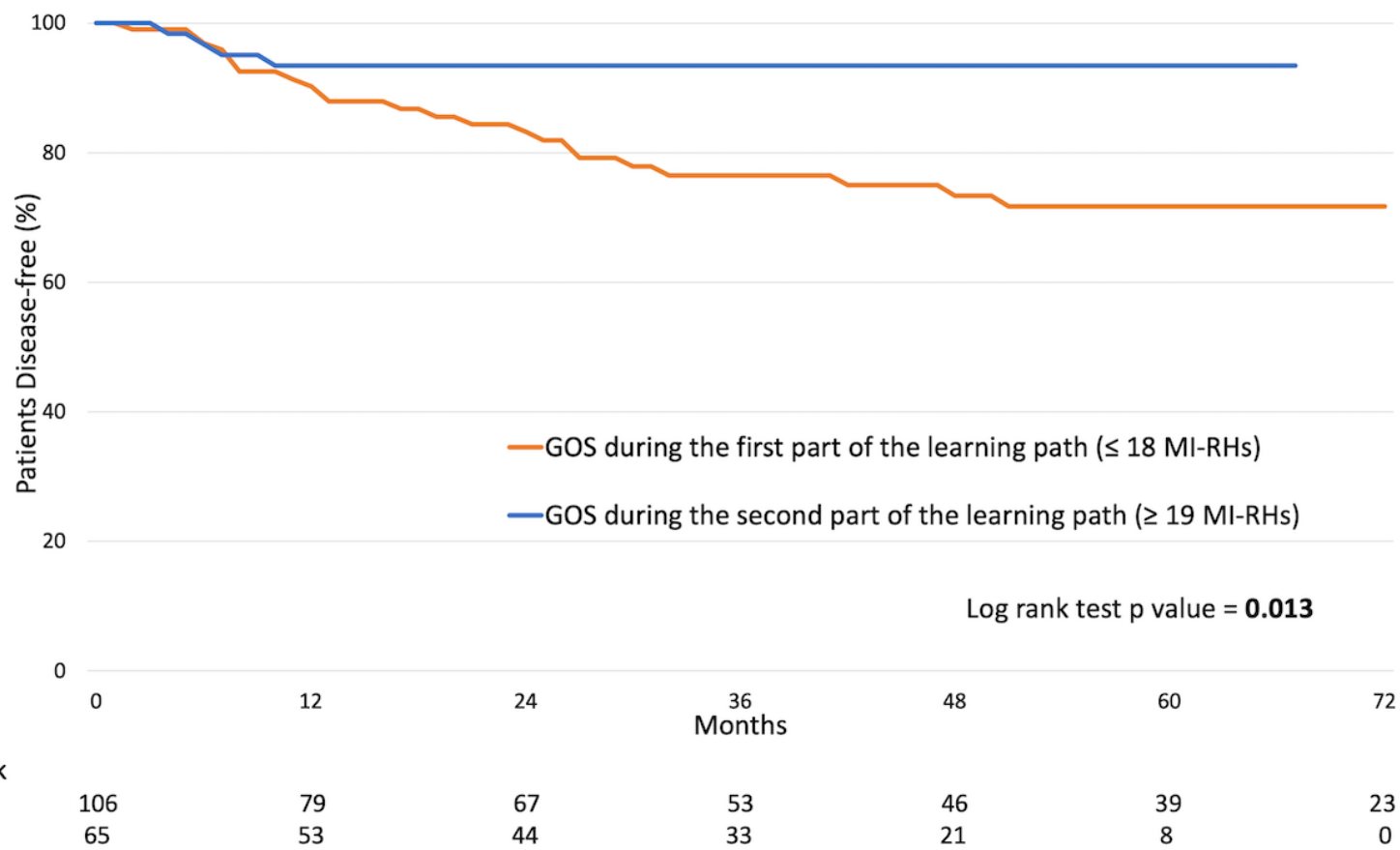

$\begin{array}{lccccccc}\text { Number at risk } & 106 & 79 & 67 & 53 & 46 & 39 & 23 \\ \leq 18 \mathrm{MI}-\mathrm{RHs} & 65 & 53 & 44 & 33 & 21 & 8 & 0\end{array}$

Supplementary figure 4: Scatter plot. - Disease-free survival curve according to GOS experience on 171 cases treated by laparoscopic approach only. 
A

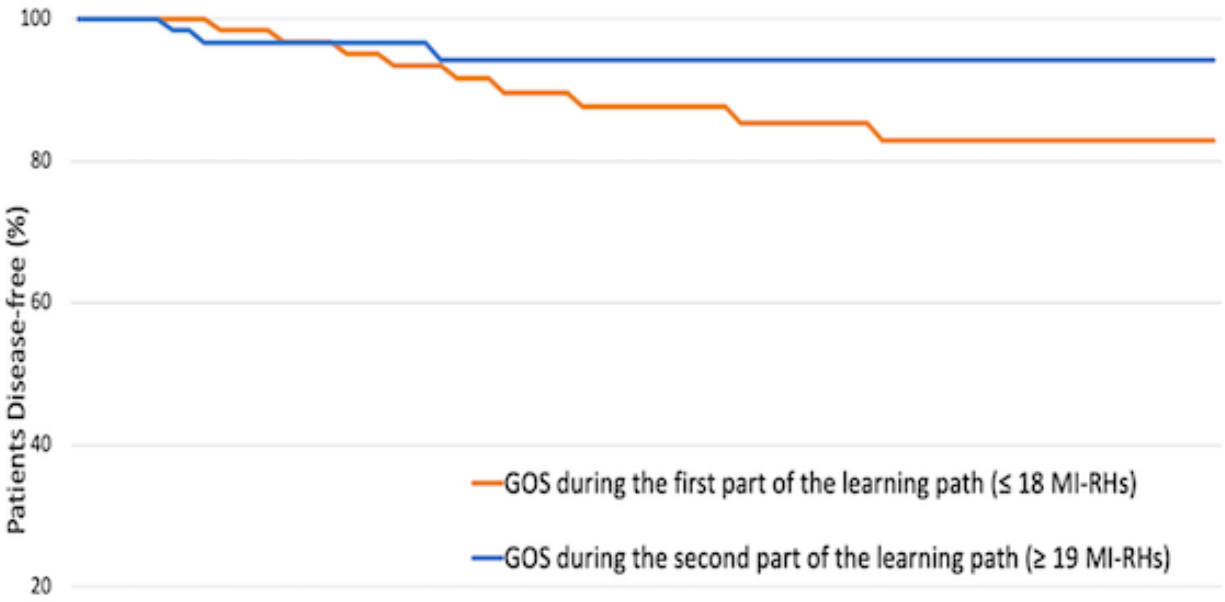

Log rank test $p$ value $=0.209$

$\begin{array}{lllllll}0 & 12 & 24 & \begin{array}{c}36 \\ \text { Months }\end{array} & 48 & 60 & 72\end{array}$

Number at risk

$\leq 18 \mathrm{Ml}$-RHs

$\geq 19 \mathrm{Ml}-\mathrm{RHS}$

85

74

55

Months

\section{B}

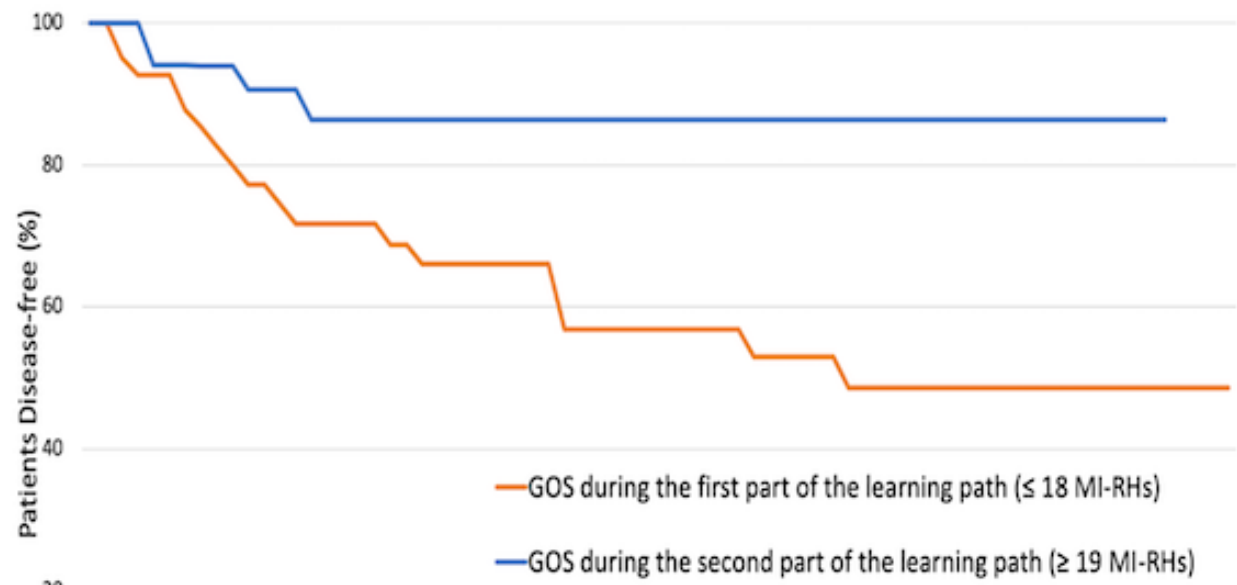

20

Log rank test $p$ value $=\mathbf{0 . 0 1 7}$

$\begin{array}{lllllll}0 & 12 & 24 & \begin{array}{c}36 \\ \text { Months }\end{array} & 48 & 60 & 72\end{array}$

Number at risk

$\leq 18 \mathrm{MI}-\mathrm{RHS}$

$\geq 19$ MI-RHs

43

35

27

25

17

11

17

Supplementary figure 5: Scatter plot. - Disease-free survival curve according to GOS experience. A: among patients with tumor diameter $<2 \mathrm{~cm}$. B: among patients with tumor diameter $>2 \mathrm{~cm}$. 